\title{
The role of axoplasmic transport in the pathogenesis of retinal cotton-wool spots
}

\author{
DAVID MCLEOD, JOHN MARSHALL, EVA M. KOHNER, AND ALAN C. BIRD \\ From the Departments of Clinical Ophthalmology and Visual Science, Institute of Ophthalmology, \\ and the Department of Medicine, Royal Postgraduate Medical School, London
}

SUMMARY Small retinal arterioles in the pig retina were occluded by argon laser photocoagulation and the morphology and topography of the resulting lesions studied by ophthalmoscopy, histology, and electron microscopy. Two days after laser coagulation ischaemic necrosis of the inner retina was observed in the territory of occluded arterioles, and swollen axon terminals packed with cytoplasmic organelles were found in the retinal nerve-fibre layer on the peripheral border of the infarcts and their border nearest to the disc. These swellings gave rise to localised zones of opacification (cotton-wool spots) at the borders of the retinal infarcts, and similar zones developed in relation to the laser burns.

Amino-acid uptake and transport in retinal ganglion cells was studied in these animals by autoradiography following an intravitreal injection of tritiated leucine. When ${ }^{3} \mathrm{H}$-leucine was injected at the same time as laser coagulation and arteriolar occlusion, label became concentrated in the swollen axon-terminals on the peripheral aspect of 2-day-old infarcts but was absent from the terminals on the disc side of infarcts. The accumulation of ${ }^{3} \mathrm{H}$-leucine and organelles was attributed to interruption of orthograde axoplasmic transport. When ${ }^{3} \mathrm{H}-$ leucine was injected into the vitreous 2 days prior to laser occlusion, label became distributed throughout the axoplasm and then accumulated in swollen axon terminals on both sides of infarcts after a further 2 days. An obstruction to both orthograde and retrograde axoplasmic flow was thus demonstrated.

We concluded that cotton-wool spots should be redefined as accumulations of cytoplasmic debris in the retinal nerve-fibre layer caused by obstruction of orthograde or retrograde axoplasmic transport in ganglion cell axons.

Cotton-wool spots are discrete opaque swellings of the inner retina found in a variety of systemic vascular disorders, including accelerated hypertension and diabetes mellitus. They consist of aggregates of 'cytoid bodies', which are the distended stumps of ganglion cell axons (Ashton and Harry, 1963), and their dense whiteness is thought to result from the light-scattering properties of cytoplasmic organelles concentrated within these terminals. Although cotton-wool spots are commonly considered to represent areas of focal retinal ischaemia, the histological and ophthalmoscopic characteristics of retinal infarction and cotton-wool spots are quite distinct. Ischaemic necrosis of ganglion-cell axons is not accompanied by organelle aggregation, and

This work was supported by the Wellcome Trust

Address for reprints: D. McLeod, FRCS, Moorfields Eye Hospital, City Road, London EC1V 2PD the inner retinal layers assume a grey translucent ophthalmoscopic appearance.

The first ultrastructural study of experimental focal ischaemia was carried out in the pig retina by Ashton et al. (1966). Within minutes of microsphere embolisation of the retinal circulation ischaemic cloudy swelling of nerve fibres developed in the territory of occluded arterioles, and as early as 5 hours after vascular occlusion organelles were found to have accumulated in axon terminals near the edge of the retinal infarcts. The aggregation of mitochondria, dense bodies, and other particles was attributed to a proliferative axonal response to hypoxia at the boundary of anoxic areas (Shakib and Ashton, 1966). However, it is known that organelles are normally synthesised only in the nerve cell body and are subsequently transported to and fro along axons between the synaptic terminals and the perikaryon (Jeffrey and Austin, 1973). This bi- 
directional movement of subcellular particles (and also molecules) is called 'axoplasmic transport', and interruption of this flow by axonal damage causes an accumulation of organelles in distended axon terminals adjacent to the injury site (Lubinska, 1964; Zelena, 1968; Banks et al., 1969). This explanation for organelle aggregation in cottonwool spots was discounted by Shakib and Ashton (1966) but can be reconciled with clinical findings in patients with retinal vascular occlusions (McLeod, 1975).

In an attempt to discriminate between these two potential sources of axoplasmic material in cottonwool spots we studied amino-acid uptake and transport in ganglion cells of the pig retina by autoradiography following an intravitreal injection of tritiated leucine. Retinal infarcts were produced by laser coagulation of small retinal arterioles. Unlike microsphere embolisation of the retinal circulation, laser occlusion permitted an accurate prediction of the size and topography of the infarcts, and also allowed comparisons to be made between axonal changes occurring in ischaemic areas and those found in relation to the severe retinal damage caused by intense photocoagulation.

\section{Material and methods}

Four healthy white pigs aged between 6 and 12 weeks old were used in this study; they were fasted for up to 18 hours prior to each anaesthetic and received no premedication. Anaesthesia was induced by halothane and oxygen from a Boyle's machine via a snout mask, and maintained with halothane, nitrous oxide, and oxygen. The pigs were laid on their right sides, so the left eye was used in each experiment.

OPHTHALMOSCOPY, PHOTOGRAPHY, AND FLUORESCEIN ANGIOGRAPHY

The pupil was dilated with cyclopentolate eye-drops $(0.5 \%)$ and phenylephrine eye-drops $(10 \%)$, and the retina was observed by direct and indirect ophthalmoscopy; the position of the eye was controlled by means of stay sutures through the 4 rectus tendons. Particular attention was paid to the topography of the inner retinal circulation and the relationship between retinal arteriolar territories and the orientation of nerve fibre bundles.

Colour photographs and fluorescein angiograms were obtained using the vertically-mounted Zeiss (Oberkochen) fundus camera and processing methods previously detailed (Dollery et al., 1966; Kohner et al., 1970); $10 \%$ sodium fluorescein was injected into the external carotid artery via a nylon catheter introduced through an ear artery.
LASER PHOTOCOAGULATION

Laser light was delivered to the eye from an argon laser photocoagulator (Coherent Radiation model 800 ) using a vertically mounted and counterbalanced slit lamp and a Worst corneal contact lens. A segment of the arteriole selected for occlusion was repeatedly exposed to $0.2 \mathrm{~s}$ pulses of irradiation with a $50-$ or a $100-\mu \mathrm{m}$ aperture and a power meter setting of 100 to $300 \mathrm{~mW}$. Arterioles in the nasal retina were most conveniently irradiated, and occlusion was facilitated by intravenous injections of fluorescein. Further applications of laser light were made if there was any evidence of reopening of an arteriole.

INTRAVITREAL INJECTION OF ${ }^{3} \mathrm{H}$-LEUCINE One milliCurie of tritiated leucine ( $\mathrm{L}-4,5^{3} \mathrm{H}$-leucine), specific activity 40 to $60,000 \mathrm{mCi} / \mathrm{mmol}$ (RadioChemical Centre, Amersham), was supplied dissolved in $1.0 \mathrm{ml}$ of $2 \%$ ethanol, to which was added $0.009 \mathrm{~g}$ of sodium chloride. A limbal conjunctival incision was made superotemporally in the experimental eye of each pig and a small quantity of vitreous was aspirated via a sclerotomy over the pars plana. $0.33 \mathrm{ml}$ of ${ }^{3} \mathrm{H}$-leucine was then injected into the posterior vitreous while the tip of the needle was observed by indirect ophthalmoscopy; the sclera and conjunctiva were then sutured. In pig No. 4 the initial vitreous aspiration proved difficult, and an anterior chamber paracentesis was performed after intravitreal injection of label in order to restore a normal intraocular pressure.

SEQUENCE (TABLE 1)

In pigs Nos. 1 and $2{ }^{3} \mathrm{H}$-leucine was injected immediately after arteriolar occlusion, that is, at about one hour from the onset of retinal ischaemia (experiment A). In pigs Nos. 3 and $4{ }^{3} \mathrm{H}$-leucine was injected into the vitreous 2 days prior to arteriolar occlusion (experiment B). In all four animals the ischaemic lesion was allowed to develop for 48 hours before enucleation; the animals were then killed by intravenous injections of potassium chloride solution.

\section{MICROSCOPY}

Immediately after enucleation, a coronal incision was made in the cornea, and the eyes were immersed

\section{Table 1}

\begin{tabular}{|c|c|c|}
\hline Day & $\begin{array}{l}\text { Experiment } A \\
\text { (Pigs No. } 1 \text { and } 2)\end{array}$ & $\begin{array}{l}\text { Experiment B } \\
(\text { Pigs No. } 3 \text { and } 1)\end{array}$ \\
\hline 1 & $\begin{array}{l}\text { Arteriolar occlusion } \\
\quad+\text { intravitreal }{ }^{3} \mathbf{H} \text {-leucine }\end{array}$ & Intravitreal ${ }^{3} \mathrm{H}$-leucine \\
\hline $\begin{array}{l}3 \\
5\end{array}$ & Enucleation & $\begin{array}{l}\text { Arteriolar occlusion } \\
\text { Enucleation }\end{array}$ \\
\hline
\end{tabular}


in $100 \mathrm{ml}$ of fixative. Initial fixation was achieved by $3 \%$ glutaraldehyde buffered in $0 \cdot 1 \mathrm{M}$ sodium cacodylate containing $10 \mathrm{mg} / \mathrm{ml}$ calcium chloride and with a final $\mathrm{pH}$ of $7 \cdot 4$. The eyes were progressively dissected in this solution and the anterior segments, together with the lens and vitreous, were discarded. After a total fixation time of $\mathbf{4 5}$ minutes a detailed drawing was made of the fundus, recording the topography of both the laser lesions and the ischaemic areas. Experimental areas were then isolated by microdissection under a dissecting microscope. Each sample was incised in such a fashion that its orientation with regard to the optic disc could be determined during ultramicrotomy. Samples were then briefly washed in $0.1 \mathrm{M}$ sodium cacodylate buffer containing $7.5 \%$ sucroses; they were then dehydrated through a graded series of concentrations of ethanol in water and embedded in Epon via epoxypropane. Subsequent procedures for light and electron microscopy were identical to those previously described (Marshall, 1970). In every sample sections were cut both parallel with and at right-angles to the axons of retinal ganglion cells.

\section{LIGHT MICROSCOPIC AUTORADIOGRAPHY}

Sections approximately $0.8 \mu \mathrm{m}$ thick were cut using glass knives in a Cambridge Huxley Mk 1 ultramicrotome and were mounted on freshly cleaned unsubbed glass slides. All subsequent handling procedures were carried out under a brown safe light (Ilford S902). Slides were coated with a nuclear emulsion (Ilford K5) using an automatic coating device (Marshall and Faulkner, 1977); they were dried horizontally for 15 minutes and then hung vertically over silica gel for 2 hours in a light-tight box. The dried coated slides were placed in small light-tight plastic boxes containing silica gel and stored at $4^{\circ} \mathrm{C}$ for 1 week. They were then developed and stained as previously described (Marshall and Voaden, 1974).

The majority of slides in this study had grain concentrations over the nerve-fibre layer of such magnitude that microscopic counting was tedious and confusing. To facilitate evaluation of the large number of sections involved, and to reduce sampling errors, slides were scanned in a Shimadzu spectrophotometer (MPS 50L) fitted with a microspectrophotometry attachment. The monitoring beam was adjusted to a size $(20 \mu \mathrm{m}$ square) such that only signals from the nerve-fibre layer were measured; changes in optical density due to the background stain (toluidene blue) were minimised by carrying out all measurements in a blue light $(550 \mathrm{~nm}, 10 \mathrm{~nm}$ half band width). Sample areas and the precise position of the monitoring beam were recorded photographically for each location on the slide.
Resuits were plotted as changes in optical density due to the concentration of grains against their location in the retinal nerve-fibre layer (Fig. 9). Grain counts from some of the less dense slides showed this method to be linear. Thus after calibration density plots could be converted into grain counts.

ELECTRON MICROSCOPIC AUTORADIOGRAPHY Sections for electron microscopic autoradiography were cut on diamond knives mounted in an OMU3 Reichert ultramicrotome. Subsequent procedures were identical to those previously described (Bok and Young, 1972) except that L4 (Ilford) emulsion diluted 1:5 was applied to the slides using the automatic coater. All slides were exposed for 4 weeks.

The large contrast range of EM6 (Ilford) photographic plates enabled the autoradiographic grains to be readily discriminated, but identification became more difficult when such plates were printed owing to the reduced contrast range of photographic papers. To avoid confusion between grains in the nuclear emulsion and organelles of similar size and density on photographic prints a masking technique was employed. Negatives of electron microscopic autoradiographs were printed on to Kodalith (Type 3 Estar 2556) film at the same size as the final print and with an exposure such that only the autoradiographic grains gave rise to an image. The film was then developed, dried, and placed on top of the paper for the final print, but slightly offset. A second exposure was made and the paper developed and fixed in the normal way. The resulting prints had a black spot from the negative reversal process and a white edge due to the mask.

\section{Results}

OPHTHALMOSCOPY AND FLUORESCEIN ANGIOGRAPHY

No pre-existing funduscopic abnormalities were noted in any of the eyes, and uniform filling of the retinal capillary bed by fluorescein was demonstrated prior to vascular occlusion. Slight haziness of the vitreous tended to obscure the fundus view after the intravitreal injection of ${ }^{3} \mathrm{H}$-leucine.

Laser coagulation of arterioles resulted in an immediate localised opacification of irradiated tissue, with obstruction to the passage of fluorescein dye along the arterioles and narrowing, darkening, and segmentation of the blood column distal to the site of occlusion. Within 2 hours of laser irradiation the inner retina in the territory of occluded vessels became swollen, highlighting the interwoven course of nerve-fibre bundles in the inner retina (Fig. 1a). The distribution of ischaemic swelling corresponded to the area of non-filling noted during the fluorescein 


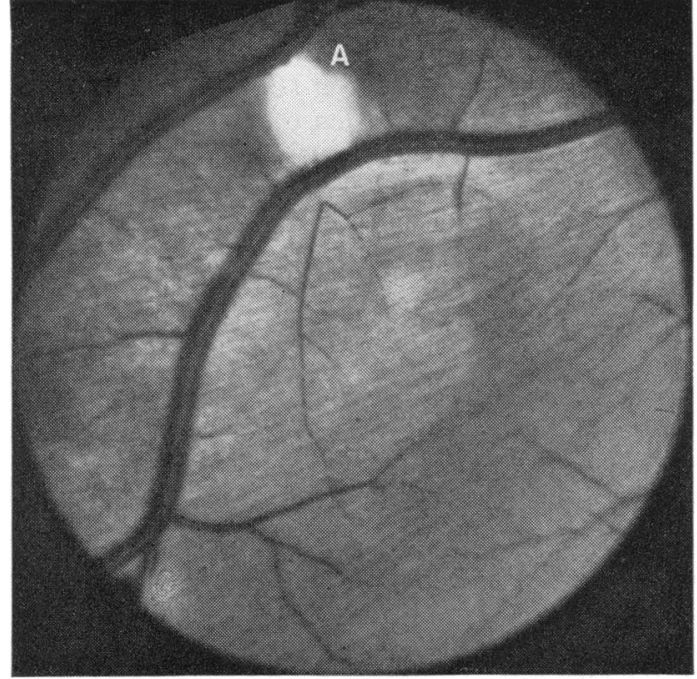

a

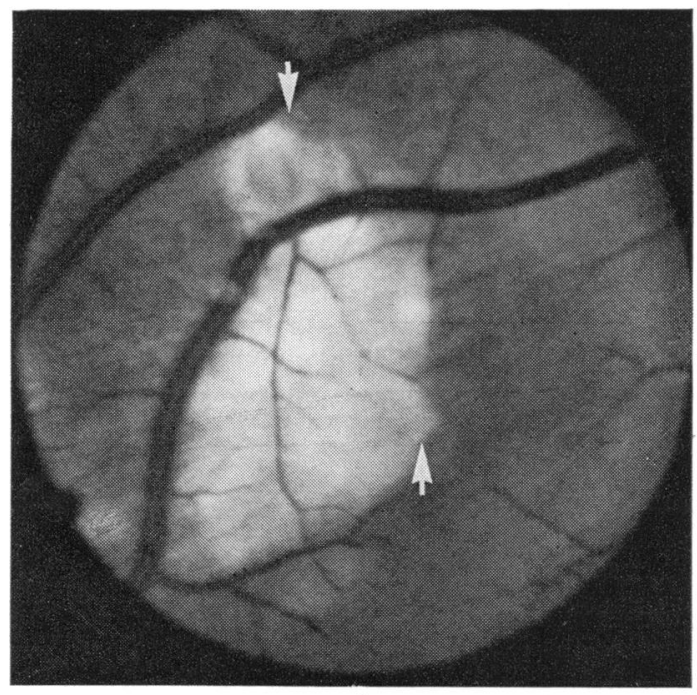

C

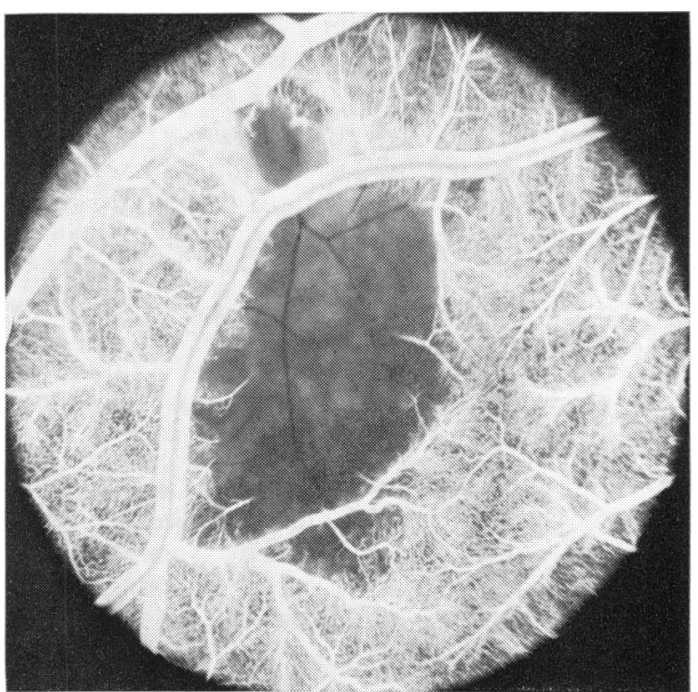

b

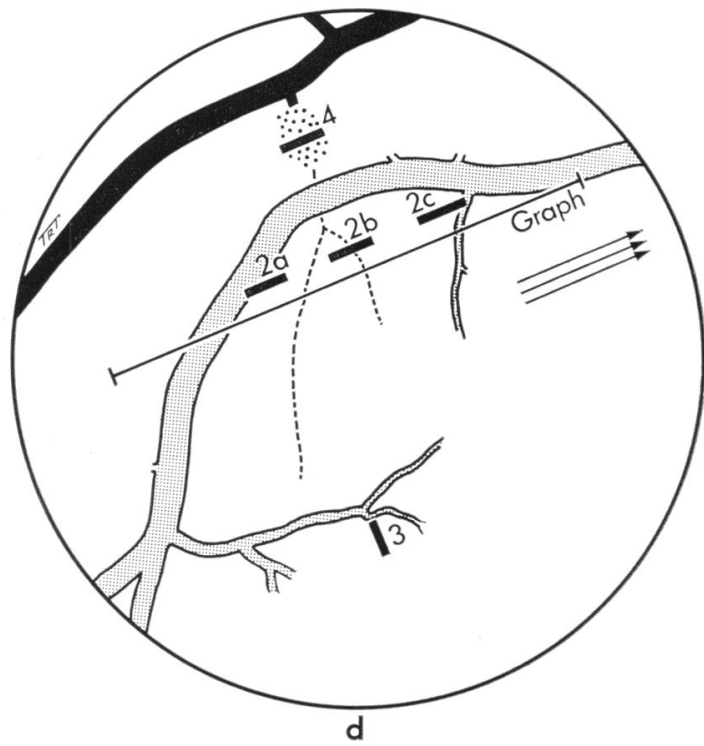

Fig. 1 (a), (b), (c), and (d) Nasal retina of pig No. 1. (a) Fundus photograph from colour transparency 2 hours after arteriolar occlusion. A is the arteriole occluded by laser photocoagulation. (b) Fluorescein angiogram 2 hours after arteriolar occlusion: early arteriovenous phase. (c) Fundus photograph from colour transparency 2 days after arteriolar occlusion. Zones of dense opacification on the disc side of the laser lesion and the infarct are arrowed. (d) Key diagram of laser lesion and ischaemic area. The orientation of nerve-fibre bundles is arrowed, and the arrows point towards the optic disc. The figure numbers of light microscopic sections are shown, and 'graph' refers to Fig. 9

angiographic transit (Fig. 1b). The surrounding retina was perfused normally, and there was gradual capillary in-filling at the periphery of ischaemic areas. No leakage of fluorescein was noted within the infarcts, but dye leaked profusely from the laser burns.
Two days after arteriolar occlusion both the laser lesions and the retinal infarcts had changed in their appearance. The central parts of laser lesions were now less opaque and localised zones of white retinal swelling were seen on either side of the irradiated areas, particularly on the disc-side of the lesions. 


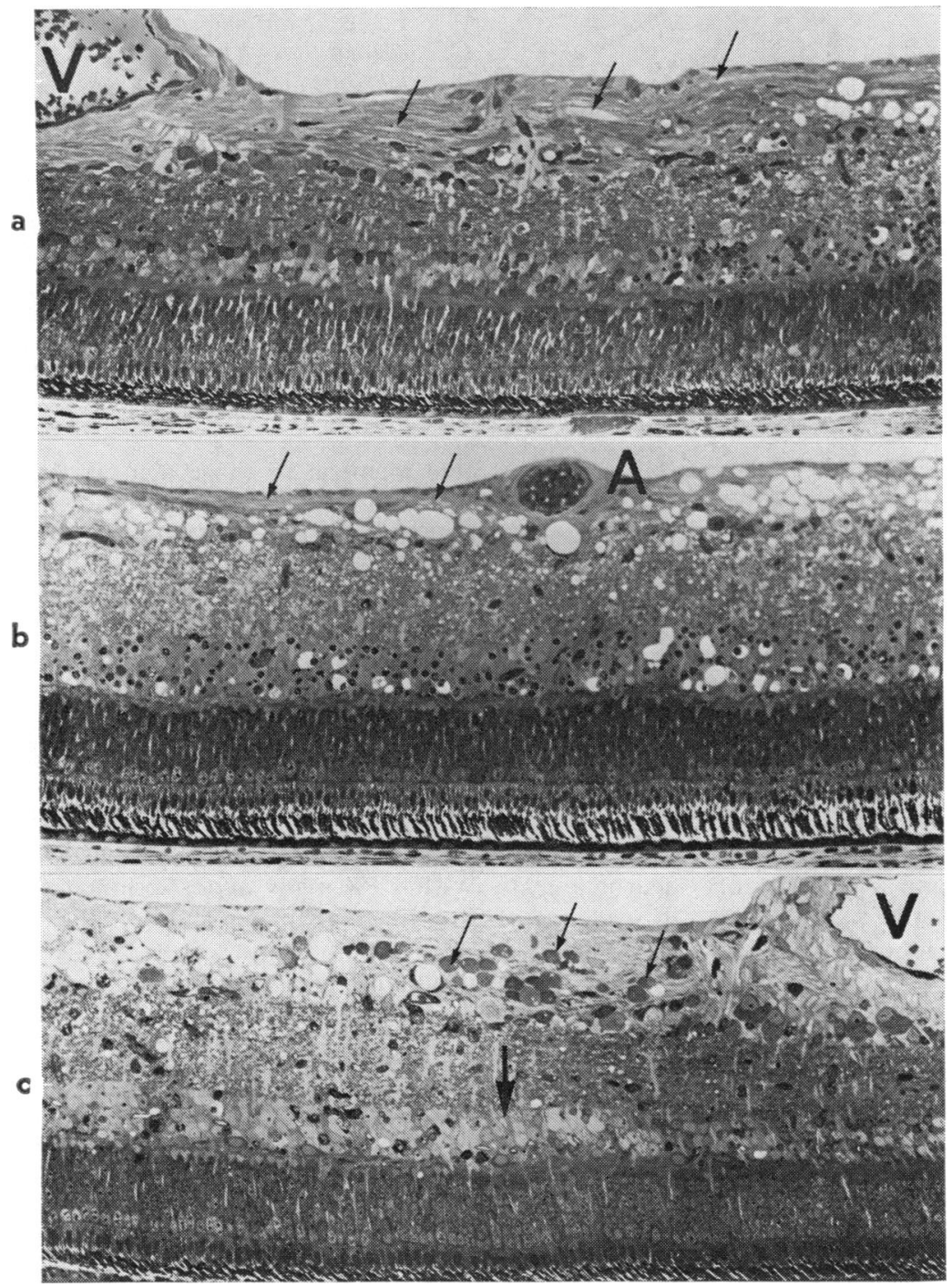

Fig. $2(a),(b)$, and (c) Light micrographs of the 3 distinctive zones associated with the ischaemic area illustrated in Fig. 1; all sections were cut along the axis of ganglion-cell axons.

(a) Zone PZ: An area characterised by abnormally swollen axons (fine arrows) in the nerve-fibre layer at the peripheral edge of the ischaemic area. $\mathrm{V}$ vein shown in Fig. 1.

(b) Zone IZ: The central part of the ischaemic area including the occluded arteriole $\mathrm{A}$. The nervefibre layer is vacuolated, and anoxic damage extends through the inner plexiform layer to the inner nuclear layer where the nuclei are pyknotic. Some nerve fibres of normal appearance are seen near the inner limiting membrane (fine arrows). The outer retinal layers appear relatively normal throughout the section.

(c) Zone DZ: The border zone on the disc side of the ischaemic area; it is characterised by spheroidal axon swellings in the nerve-fibre layer (fine arrows). The coarse arrow marks the limit of ischaemic changes in the deeper layers of the inner retina; $\mathrm{V}$ is a vein seen in Fig. 1. $\times 180$

The ischaemic inner retina had become more translucent and swollen than at 2 hours, and the nerve fibre bundle striation could no longer be readily defined. Furthermore, a zone of denser opacification had developed in the nerve-fibre layer where nerve fibres crossed the borders of ischaemic areas. Again, this swelling was most noticeable on the disc side of infarcts (Fig. 1c), especially in the peripapillary region, where the nerve-fibre layer was thickest. The infarcts remained poorly perfused by dye on fluorescein angiography.

\section{LIGHT MICROSCOPY}

In the territory of occluded arterioles changes were seen in all layers of the inner retina while the receptor cells and pigment epithelium remained undamaged; only abnormalities in the nerve-fibre layer will be described in detail. Pathological changes in ganglioncell axons occurred in three zones which merged into each other: (i) a zone at the peripheral edge of the ischaemic area away from the optic disc (PZ), (ii) an intermediate zone (IZ), and (iii) a zone at the edge of the ischaemic area adjacent to the disc (DZ). The extent of these regions varied between individual lesions, but they were always sufficiently distinct to be recognised morphologically. Representative examples of these zones are shown in sections cut parallel to the axis of ganglion-cell axons (Fig. 1d; Fig. $2 a, b, c)$.

Most ganglion-cell axons become swollen near 


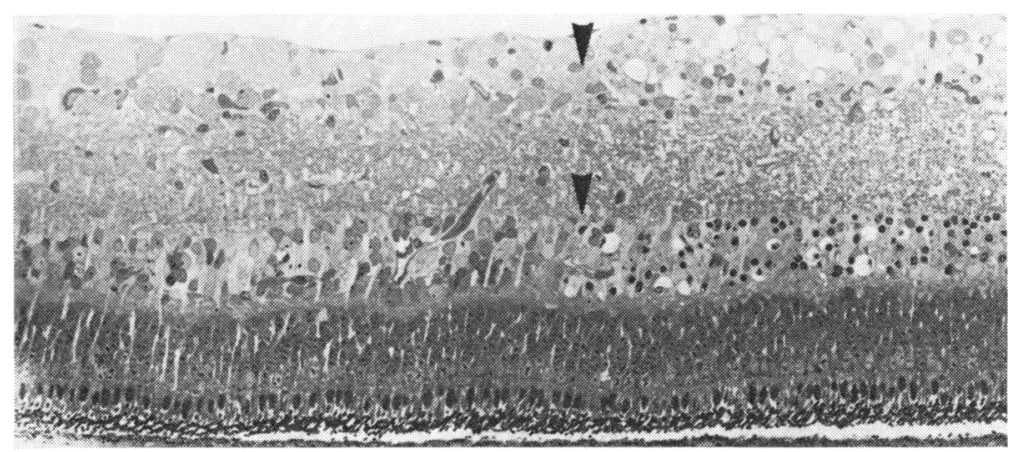

Fig. 3 Light micrograph of the edge of the ischaemic area illustrated in Fig. 1; the plane of this section is at right-angles to the long axis of ganglion-cell axons. There is a sharp transition (arrowed) between normal tissue and ischaemic retina characterised by vacuolation in the nerve-fibre layer and nuclear pyknosis in the inner nuclear layer. There is no transitional zone of axonal swelling in the nerve-fibre layer. $\times 180$

the peripheral edge of an ischaemic area, producing the region PZ. However, this was a relatively diffuse region, and axons often penetrated some way into this area before significant swelling was seen. There was a more abrupt transition between normal and ischaemic tissue in the ganglion cell and deeper layers of the inner retina, where shrunken pyknotic nuclei could be seen (Fig. $2 a$ ).

In the intermediate region (IZ) the nerve-fibre layer was extremely vacuolated and contained fewer axons than equivalent non-ischaemic retina (Fig. $2 b$ ). This loss of fibres was seen most clearly in sections from the edge of the lesion cut at right-angles to the long axis of the axons (Fig. 3), and a majority of those axons remaining within IZ were either shrunken or swollen. In most lesions the least affected axons were concentrated on the vitreal aspect of the nerve-fibre layer.

The border zone DZ (on the disc side of a retinal infarct) was more circumscribed than that on the peripheral aspect of the infarct. In this zone, large spheroidal axon swellings (sometimes designated 'cytoid bodies') were observed where axons emerged from the area of ischaemia, which was defined by another relatively abrupt transition from necrotic to normal tissue in the layers of the inner retina deep to the nerve-fibre layer (Fig. 2c).

Pathological changes in axon segments adjacent to laser burns were identical to those seen at the borders of retinal infarcts despite the different mechanism of axonal interruption. Differences in axonal responses in region $\mathrm{PZ}$ compared with $\mathrm{DZ}$ were readily demonstrable, since these zones were closer together in the laser lesions (Fig. 4).

\section{ELECTRON MICROSCOPY}

Retinal ganglion-cell axons varied in cross-sectional diameter between 0.25 and $1.50 \mu \mathrm{m}$ in control areas of pig retina. Peripheral to the edge of an ischaemic area some swollen axons ( 3 to $5 \mu \mathrm{m}$ diameter) were observed containing abnormal concentrations of neurofilaments. Within PZ many axons terminated in swellings of 3 to $10 \mu \mathrm{m}$ diameter and contained abnormally dense concentrations of organelles. Typically, the neurotubular array within these axons was disorganised, and neurofilaments were concentrated in the centre of axons with many small mitochondria lining the axolemma (Fig. 5a). However, in the largest axons this arrangement was lost and the mitochondria and vesicular inclusions became distributed throughout the axoplasm. The swellings sometimes contained dense inclusions, some of which appeared to be lysosomes, while others were larger and resembled the lipid bodies that are associated with the breakdown of membrane systems.

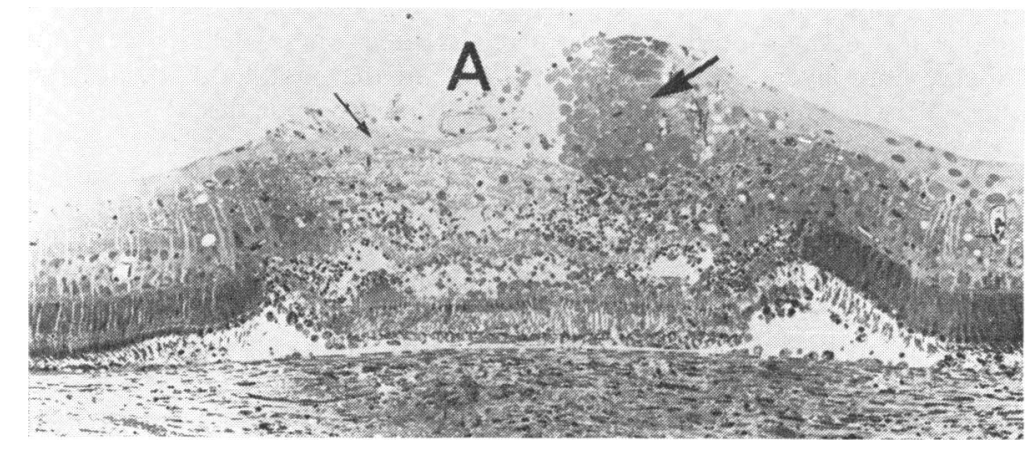

Fig. 4 Light micrograph of the laser irradiated area which resulted in occlusion of the arteriole A illustrated in Fig. I. $A$ zone of axonal swelling is seen on the peripheral aspect of the lesion (fine arrow), and globular axon swellings are present on the disc side of the lesion (coarse arrow). Within the irradiated zone the nervefibre layer is destroyed together with the inner limiting membrane. $\times 180$ 


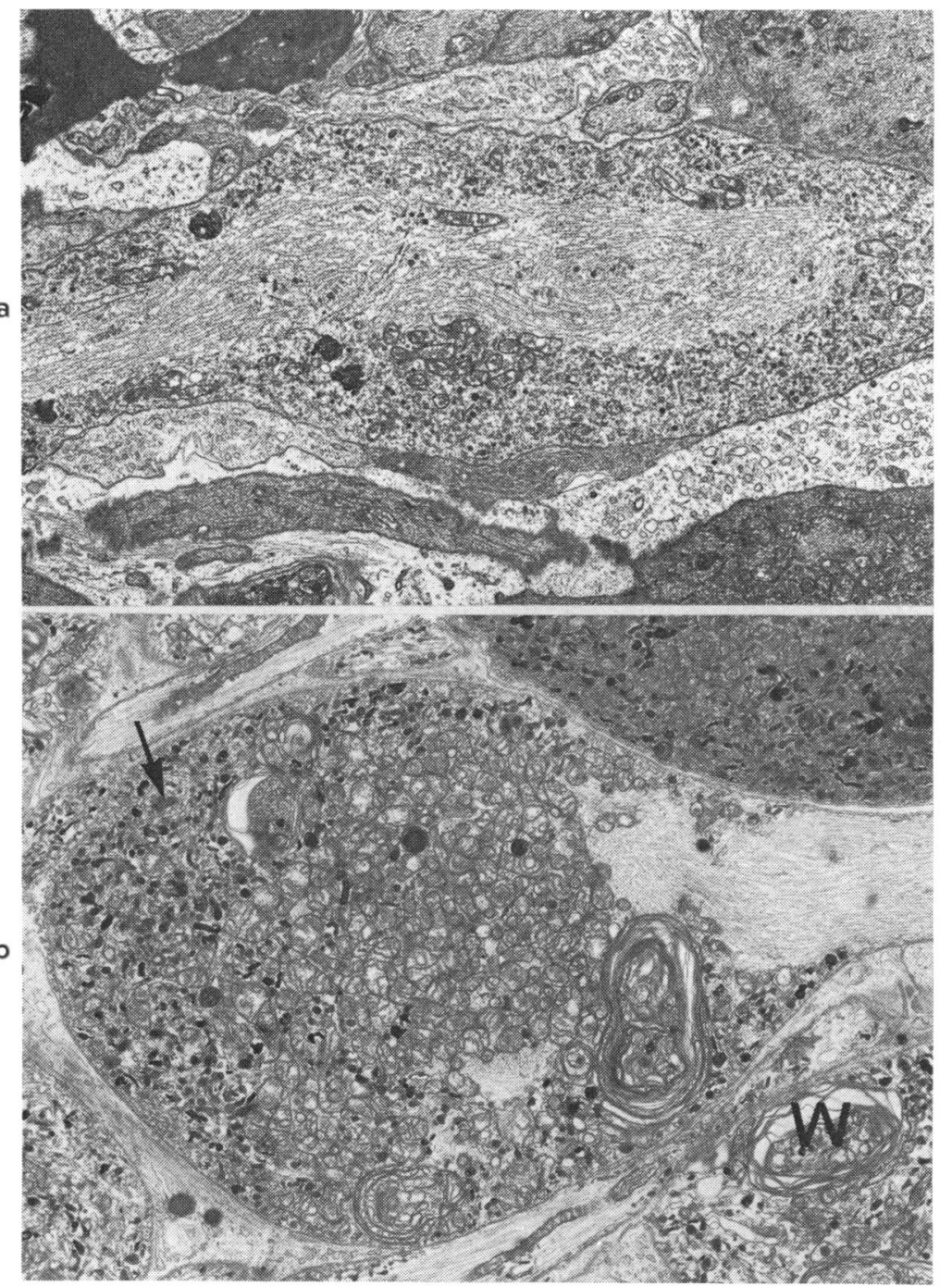

Fig 5 (a) and (b) Electron micrographs of axonal swellings in zones $P Z$ and $D Z$ adjacent to the ischaemic area illustrated in Fig. 1.

(a) Axons in PZ are characterised by an elongated swelling with an aggregation of neurofilaments centrally and an accumulation of mitochondria and other organelles adjacent to the axolemma.

(b) Axon terminals in $D Z$ are globular and contain dense concentrations of mitochondria, many of which are shrunken and degenerate (arrow), together with membranous whorls $\mathbf{W}$. $\times 6300$

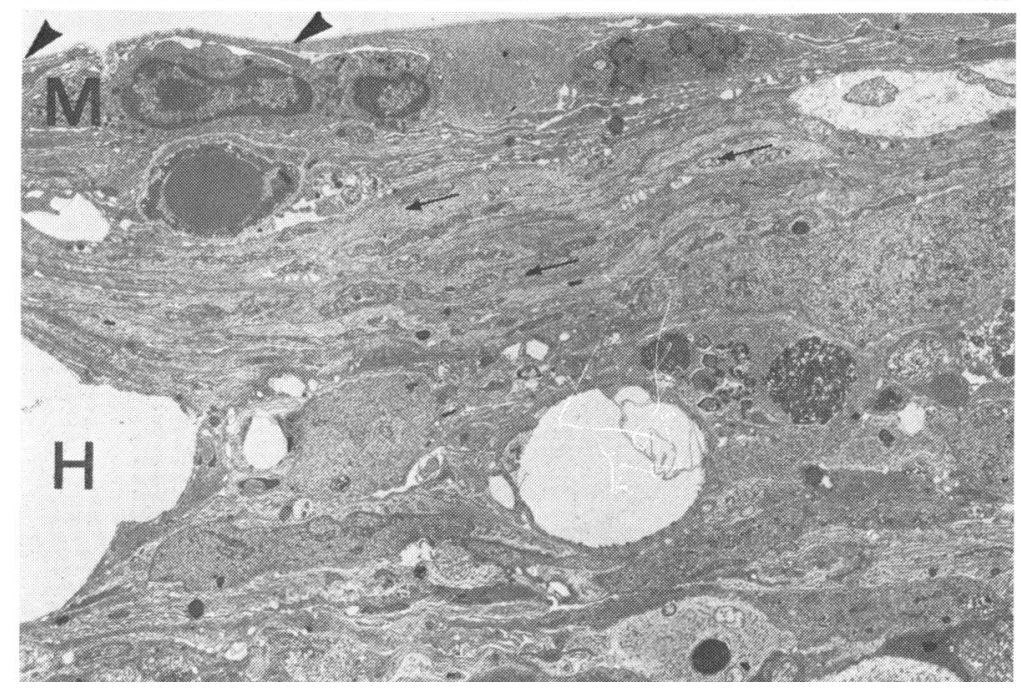

Fig. 6 Electron micrograph of the nerve-fibre layer within the central zone (IZ) of the ischaemic area illustrated in Fig. 1. Degenerative processes affecting axons include vacuolation $\mathrm{H}$ and intra-axonal densification. Axons of relatively normal appearance (fine arrows) are seen beneath the inner limiting membrane (coarse arrows) together with macrophages $\mathrm{M} . \times 3400$ 
a
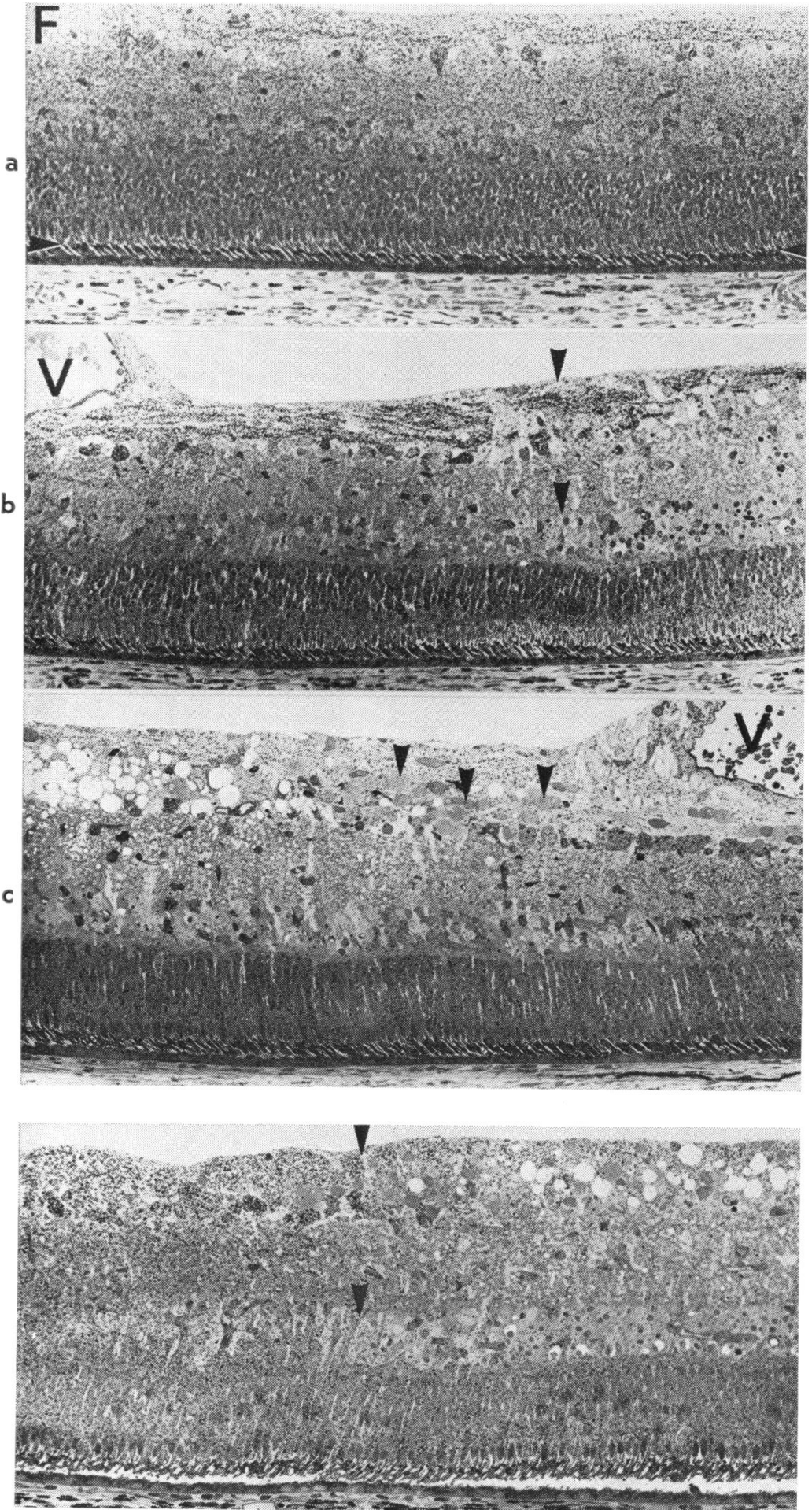

Fig. $7(a),(b)$, and (c) Light microscopic autoradiographs of ${ }^{3} \mathrm{H}$-leucine incorporated into the retina of pig No. 1 (experiment A): sections were cut along the axis of ganglion-cell axons.

(a) A control area showing ${ }^{3} \mathrm{H}$-leucine uptake into the retina, with high concentrations of label over the nerve-fibre layer $\mathrm{F}$ and over the ciliary regions of photoreceptor outer segments (arrowed).

(b) Autoradiograph showing ${ }^{3} \mathrm{H}$-leucine distribution at the peripheral edge (arrowed) of the ischaemic area. An extremely high concentration of label is associated with the area of axonal swelling $(P Z) . V$ is a vein in Fig. 1.

(c) Autoradiograph showing ${ }^{3} \mathrm{H}$-leucine distribution in zone $D Z$. Grains are absent over the spheroidal axon swellings in this region (arrowed). The grains over the innermost part of the nerve-fibre layer reflect the presence of surviving axons beneath the inner limiting membrane. $\mathrm{V}$ is a vein in Fig. 1 . $\times 180$

Fig. 8 Light microscopic autoradiograph through the edge (arrowed) of the area of ischaemia in Fig. 1; the plane of section is at right-angles to the axis of ganglion-cell axons. No grains are seen over vacuolated or densely staining axons within the ischaemic area, but there are comparable grain densities over axons outside this area and surviving axons beneath the inner limiting membrane within the area of ischaemia. $\times 180$ 
Within the intermediate zone (IZ) extreme axonal damage was seen. Many axons were devoid of organelles and remained only as membrane-bound vacuoles, while others contained an amorphous remnant of the axoplasm together with shrunken or swollen mitochondria. In some areas the membranes bounding the axon ghosts had burst and irregular vacuoles were formed that extended over large areas of the nerve-fibre layer. Alternatively, some of the damaged fibres were shrunken and so electron-dense that no substructure could be determined. However, apparently normal axons were also identified among damaged axons in the inner part of the nerve-fibre layer.

The spheroidal axonal swellings seen in region $\mathrm{DZ}$ measured 10 to $15 \mu \mathrm{m}$ in diameter and contained vast numbers of either shrunken or swollen mitochondria. Large numbers of neurofilaments were usually seen adjacent to this concentration of mitochondria in the part of the axon running away from the lesion towards the optic disc, but few if any neurotubules were observed. Many terminals contained the electron-dense lipid bodies previously described, and almost all contained membranous whorls which characterise degenerating membrane systems (Fig. $5 b$ ).

Macrophages were observed throughout the ischaemic area but were most abundant around capillaries and within the abnormally distended extracellular space beneath the inner limiting membrane; a large number of these cells contained accumulations of lipid globules (Fig. 6). The Müller's fibres appeared relatively normal, but some contained lipid globules and other membranous whorls.

The ultrastructural changes in the nerve-fibre layer in relation to laser lesions were similar to those described above. Areas PZ and DZ were more discrete, however, and the central region contained few if any normal fibres. Indeed, the majority of axons in this irradiated zone IZ were unrecognisable, while the remnants were either granular aggregations of coagulated protein or membrane-bound vacuoles.

\section{AUTORADIOGRAPHY}

Two distinct patterns of grain distribution could be observed in the nerve-fibre layer in relation to ischaemic areas, the distinction depending on the time at which ${ }^{3} \mathrm{H}$-leucine was injected into the animals. Uptake into the outer retinal layers was similar in all experiments and identical to that of control tissue (Fig. 7a).

\section{Experiment $A$}

Dense localised accumulations of grains were found at the peripheral edge of ischaemic areas, with tracts of grains clearly visible traversing $\mathrm{PZ}$ and penetrating various distances towards the central zone IZ before terminating in a bulb-like distribution of extremely high grain density (Fig. $7 b$ ). A relatively high grain distribution was also observed over the nerve-fibre layer peripheral to $\mathrm{PZ}$ when compared with control tissue. This increase in grain density became less marked with increasing distance peripherally from PZ. The axon terminals in DZ were always devoid of grains, and this lack of grains extended for some distance along the nerve-fibre layer towards the optic disc (Fig. 7c).

A reduced grain count was found in IZ when compared with control tissues and any high localised counts were always associated with tracts of surviving axons extending from PZ. In addition, a few grains were found beneath the inner limiting membrane throughout the ischaemic area. The relatively low grain count in IZ was best demonstrated in sections taken from the edge of the lesion and cut at right-angles to the long axis of the axons (Fig. 8).

These observations were verified and quantified by scanning the sections in the spectrophotometer. A typical example of axonal grain distribution in relation to an ischaemic area is shown in Fig. 9.

Electron microscopical autoradiographic preparations further clarified the grain distribution described

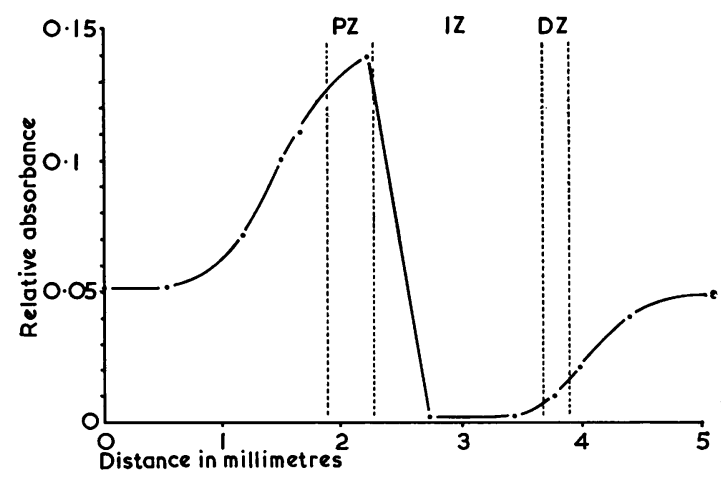

Fig. 9 Graph showing variation in relative absorbance (optical density) in the nerve-fibre layer with position in the retina as measured on a spectrophotometer. This is a typical trace and derives from sections taken along the line marked in Fig. 1 (d). The base line was set on the lowest density sample, and a suitable range selected to give a full scale deflection in the densest areas. The relative absorbance gives a measure of variation in grain density throughout the specimen. $P Z=$ zone of proximal axon terminals at the peripheral edge of the ischaemic area. $I Z=$ intermediate zone of inner retinal infarction. $D Z=$ zone of distal axon terminals on the disc side of the ischaemic area 


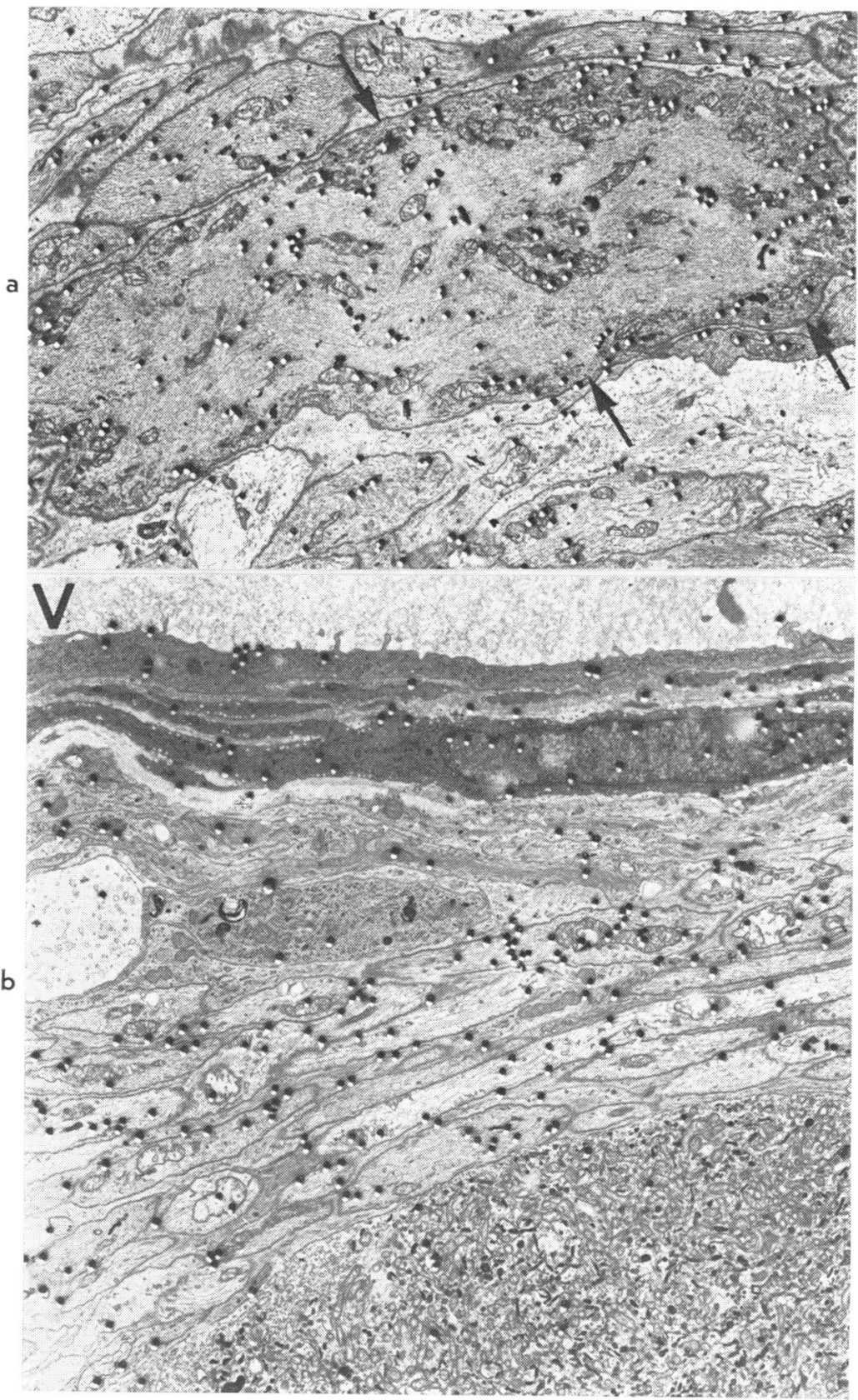

Fig. 10 (a) and (b) Electron microscopic autoradiographs showing the distribution of ${ }^{3} \mathrm{H}$-leucine in an axon terminal from $P Z$ compared with that in a spheroidal terminal from $D Z$ in experiment A (pig No. 1). Tonal contrasts in grains were achieved by a masking technique (see methods).

(a) $A$ dense accumulation of grains is characteristic of swollen axons in $P Z$, and most of this label is associated with the organelles juxtaposed to the axolemma (arrowed).

(b) The spheroidal axon terminal from $D Z$ is virtually free of grains as in Fig. 7 (c). Occasional grains seen over the distal axon terminal are not significant when background and resolution are taken into account. $\mathrm{V}$ is the lumen of the vein in Fig. 1. $\times 5580$

above. Grains were associated with both glial and axonal components of the nerve-fibre layer in the control areas of retina. In region PZ high grain densities were observed over the areas of axonal swelling and mitochondrial aggregation (Fig. 10a). No grains were found over areas of vacuolation in IZ (given the resolution of this technique (Salpeter et al., 1969; Gupta et al., 1973)), and grains were again absent over the spheroidal axon terminals in region DZ (Fig. 10b).

\section{Experiment $B$}

By light microscopical autoradiography a similar though less dense grain accumulation was found in 
region $\mathrm{PZ}$ when compared with experiment $\mathrm{A}$. In these sections tracts were also observed extending towards IZ, but the contrast of grain density was reduced because of the increase in the general grain density in IZ. The axon terminals in zone $\mathrm{DZ}$ were also associated with relatively dense localisations of autoradiographic grains (Fig. 11), and increased grain densities could be seen extending away from both PZ and DZ. Electron microscopic autoradiographic preparations of tissue from B-type experiments confirmed the above observations; grains were clearly seen associated with the distal axon terminals in area DZ (Fig. 12).

The differences in grain distribution in experiment A compared with experiment B were also clearly demonstrable in autoradiographs from laser lesions, where the zones $\mathbf{P Z}$ and $\mathrm{DZ}$ were in closer proximity (Fig. 13).

\section{Discussion}

Swollen axon terminals develop on either side of injuries to myelinated and unmyelinated nerve fibres of both the peripheral and central nervous systems (Perroncito, 1907; Ramon Y Cajal, 1928). In the nerve-fibre layer of the retina terminal swellings have been described on either side of axonal interruptions caused by intense photocoagulation or sectioning, and appear to be responsible for localised opaque swelling of an otherwise transparent inner retina (Okun and Collins, 1962; Wolter and Moorman, 1966; Goldberg and Galin, 1973). In our study swollen terminals were also found on both sides of axon segments damaged by ischaemia, which is in keeping with the clinical topographical observation that localised zones of white swelling develop on both the peripheral and disc-adjacent borders of grey retinal infarcts after retinal vascular occlusions (McLeod, 1975). The ophthalmoscopic delineation of these border zones was sometimes difficult in our experiment owing to the thinness of the nerve-fibre layer of the nasal retina of pigs, but these zones were clearly defined histologically. Our findings are at variance with the view that only swollen axon terminals on the cell body side of ischaemic axon segments are important in the pathogenesis of retinal cotton-wool spots (Wolter, 1959; Shakib and Ashton, 1966; Ashton, 1970).

\section{PATHOGENESIS OF AXONAL SWELLING}

The development of terminal swellings on the stumps of interrupted axons suggested to Cajal a 'regenerative phase of survival of axons before the final withering' (Ramon Y Cajal, 1928). The axon swellings have subsequently been shown to contain aggregations of those organelles which are normally distributed along the length of the axon, together with an accumulation of proteins including enzymes (Lubinska, 1964). Quantitative studies and doubleligation experiments indicate that the enzymes concentrated in axon terminals, including some localised within mitochondria, are derived from uninjured parts of the axons, and are not synthesised locally (Lubinska, 1964; Banks et al, 1969). Their accumulation has been attributed to a damming-up of the normal bidirectional flow of axoplasmic constituents along axons, which necessarily requires that axoplasmic flow continues for some time after axonal section-Cajal's 'agony of the axons'. Interruption of orthograde axoplasmic transport results in an accumulation of axonal material on the proximal side of an injury, while obstruction to retrograde transport gives rise to a distal accumulation; similar accumulations occur whatever the type of axonal injury whether traumatic, thermal, toxic, or anoxic.

Axoplasmic transport in retinal ganglion cells has the same essential characteristics as in other nerve

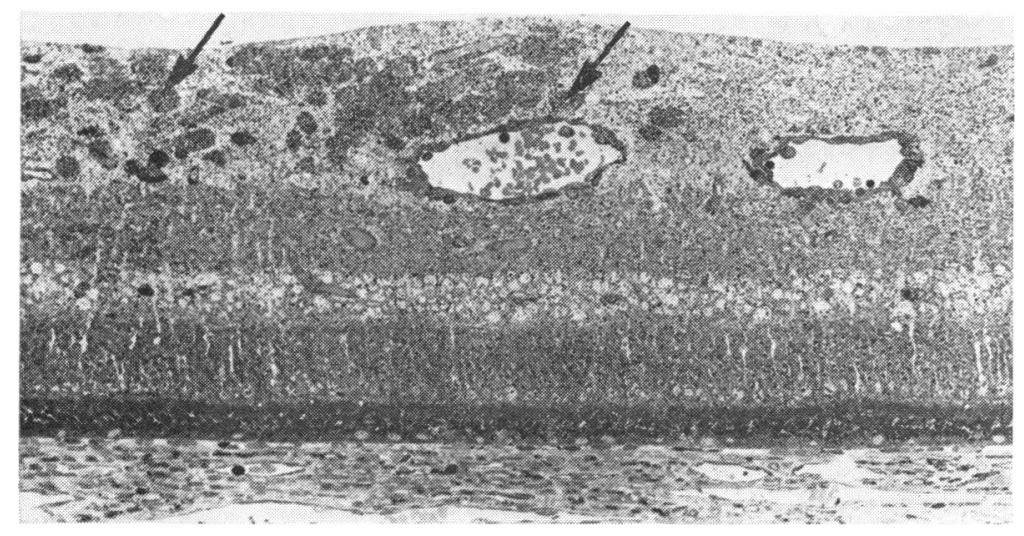

Fig. 11 Light microscopic autoradiograph showing the zone $D Z$ of the ischaemic area in pig No. 3 (experiment B), the section was cut along the axis of ganglion-cell axons. The spheroidal axon terminals (arrowed) are associated with a high concentration of ${ }^{3} \mathrm{H}$-leucine. $\times 180$ 


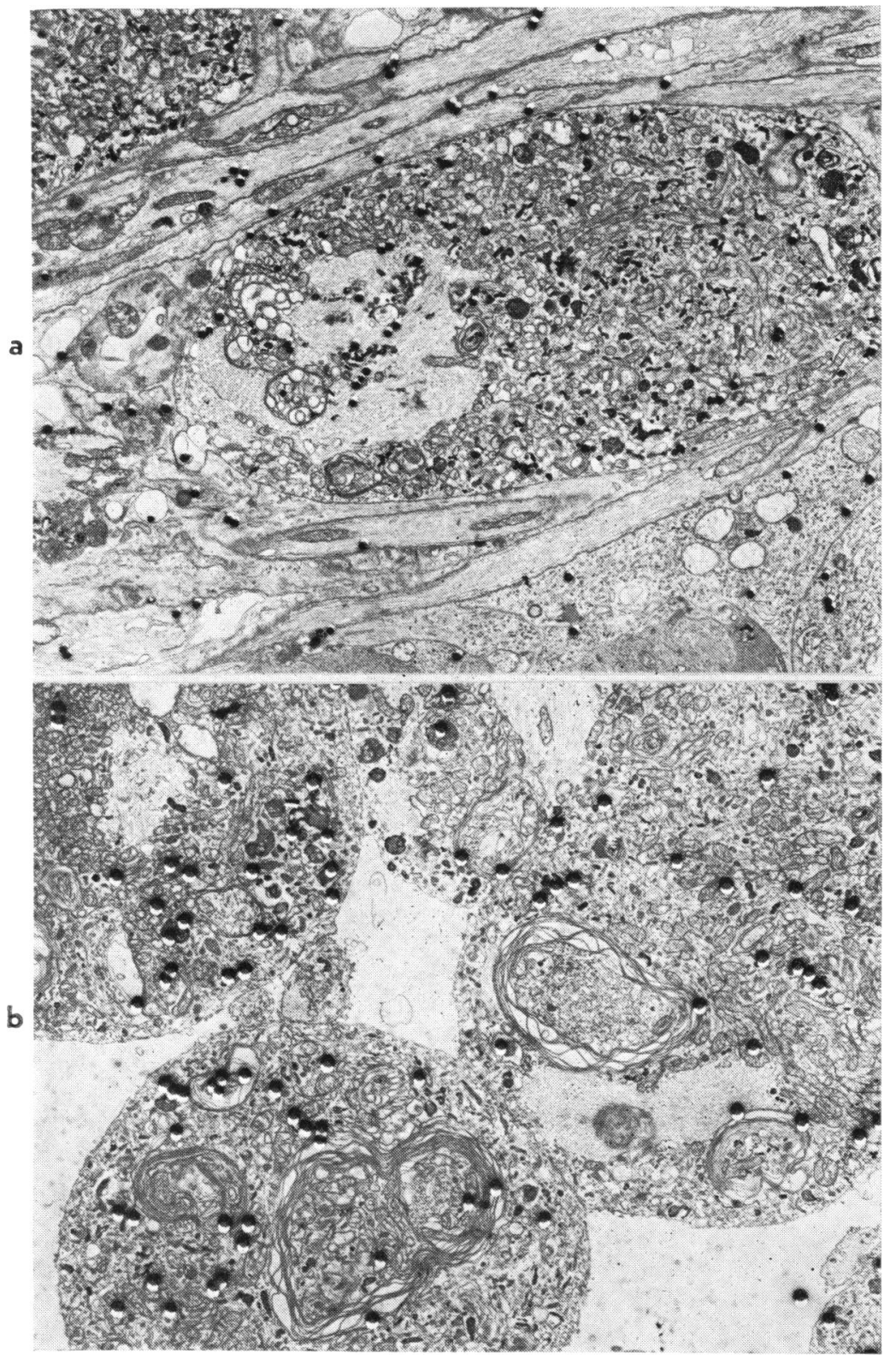

Fig 12 (a) and (b) Electron microscopic autoradiographs from zone $\mathrm{DZ}$ of the ischaemic area in pig No. 3 (experiment $B)$. The globular axon swellings were sectioned (a) along the axis of the axons, and (b) at right-angles to the axis of the axons. Both micrographs show many grains associated with these axon terminals.

(a) $\times 5250$; (b) $\times 6500$

cells (McEwen and Grafstein, 1968; Chou, 1970; Hendrickson, 1972). To date ophthalmological research has been directed almost exclusively to obstruction of axoplasmic flow at the optic nerve head. Interruption of orthograde ${ }^{3} \mathrm{H}$-leucine transport and an accumulation of organelles have been reported, for example, in experimental glaucoma and papilloedema (Anderson and Hendrickson, 1974; Tso, 1976), though the exact cause of the obstruction to axoplasmic flow in these conditions has not been identified. In our study obstruction of axoplasmic transport in axon segments within the retina was demonstrated by autoradiography; the findings are summarised in Fig. 14. In experiment A, in which ${ }^{3} \mathrm{H}$-leucine was injected at the time of laser coagulation and arteriolar occlusion, label became concentrated in swollen axon terminals on the peripheral aspect of infarcts (PZ) but was absent from the distal axon terminals of zone $\mathrm{DZ}$, indicating an obstruction to orthograde axoplasmic transport 

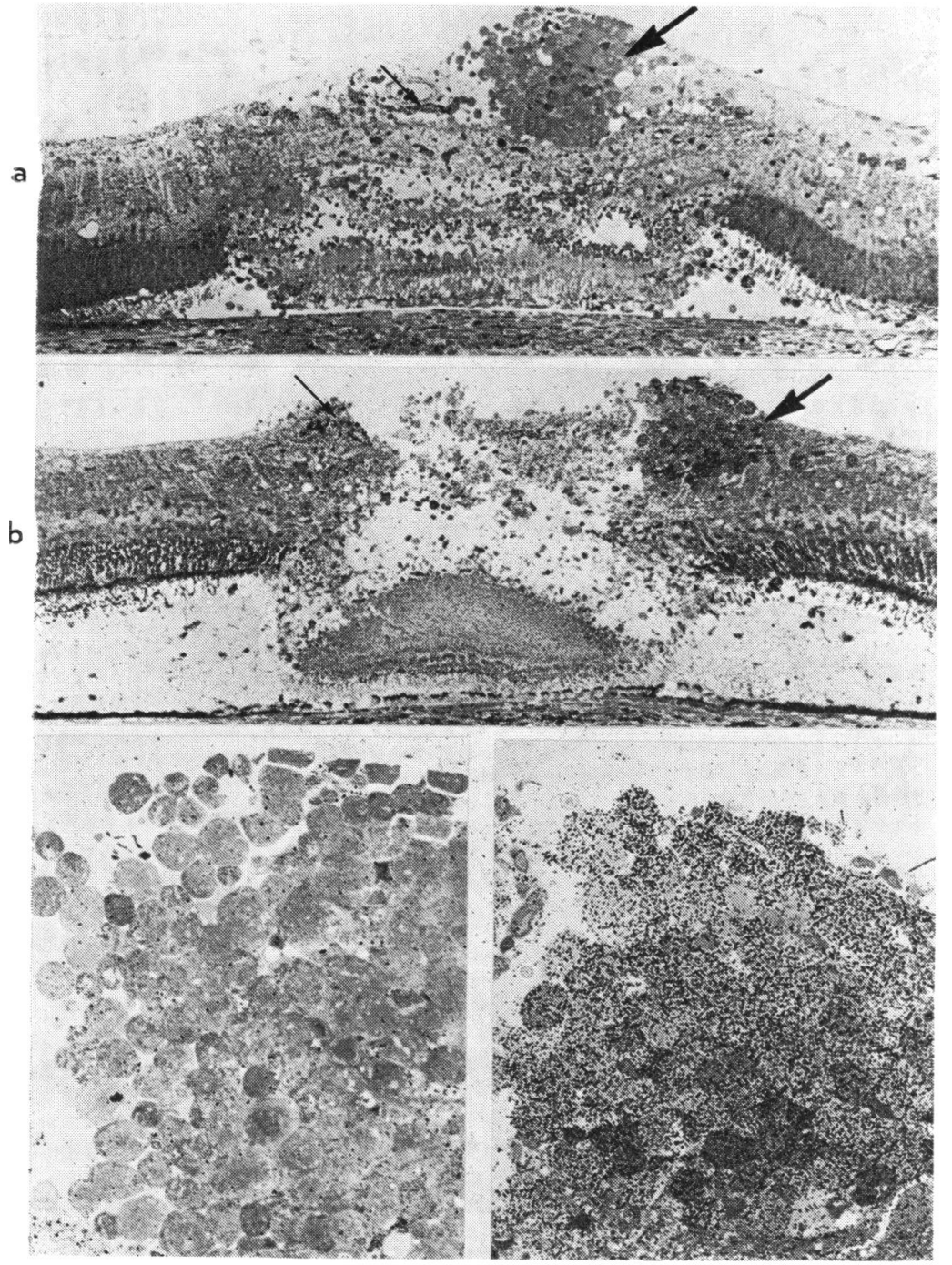

C

in axons damaged by ischaemia. In experiment $B$ 2 days were allowed for ${ }^{3} \mathrm{H}$-leucine to be incorporated within ganglion cells and become distributed throughout the axoplasm prior to laser occlusion (Chou, 1970; Hendrickson, 1972). Label became concentrated in axon swellings on both sides of the ischaemic areas after a further two days. Studies of a similar design were previously carried out by Lasek (1967) and Ochs (1975) using peripheral nerves, and the build-up of label in proximal and distal axon terminals was attributed to obstruction of orthograde and retrograde axoplasmic transport, respectively.

Shakib and Ashton (1966) considered that the various organelles which accumulate in axon terminals at the edge of retinal infarcts proliferate at
Fig. $13(a),(b),(c)$, and (d) Light microscopic autoradiographs of laser-induced lesions from experiment $A((a)$ and $(c))$ and experiment $B$ (b) and (d)); sections were cut along the axis of ganglioncell axons.

(a) Autoradiograph showing the concentration of ${ }^{3} \mathrm{H}$-leucine in $\mathrm{PZ}$ (fine arrow) and the absence of label in axon terminals in $D Z$ (coarse arrow) in experiment $A$.

(b) Autoradiograph showing a high concentration of label in $D Z$ (coarse arrow) as well as in $P Z$ (fine arrow) in experiment $B$.

(c) High power light microscopic autoradiograph from the area DZ in Fig. 13 (a) (experiment $A$ ). The limited number of grains may be accounted for by glial uptake and background.

(d) High power light microscopic autoradiograph from the area $D Z$ in Fig. 13 (b) (experiment B). An extremely dense concentration of grains is seen over the spheroidal axon terminals.

(a) and (b) $\times 180$;

(c) and (d) $\times 330$ 
their aggregation in $\mathrm{PZ}$, so axon hillock changes in ganglion cells within the infarct are irrelevant to this discussion.

There was some minor morphological variation in adjacent axon terminals within PZ and DZ 2 days after axonal injury, but striking differences were seen if axon swellings on opposite sides of infarcts were compared - that is, $\mathbf{P Z}$ compared with DZ. After 2 days' development the proximal swellings were elongated or tapered and contained relatively well preserved mitochondria (Fig. 5a), while distal terminals had a spheroidal shape and contained mitochondria in various stages of degeneration (Fig. 5b). This is a new observation in respect of focal retinal ischaemia, and probably reflects the fact that proximal axon terminals remain in dynamic communication with the perikaryon while the distal part of the axon is no longer so connected.

The axon terminals adjacent to retinal infarcts showed no significant difference in either shape or organelle content from those on each side of laser burns, and the autoradiographic findings were identical in each type of lesion; the pathogenesis of axonal swelling was undoubtedly the same in each case. While all axons passing through laser burns were totally and irreversibly disrupted, however, varying degrees of axonal injury were seen in relation to retinal infarcts. Axon terminals were typically found in the deeper parts of the nerve-fibre layer at the edge of infarcts, while some axons near the vitreal surface of the retina showed little morphological change, and continuing orthograde axoplasmic transport across the ischaemic area was demonstrated in these neurones. The maintenance of axonal structure and function beneath the inner limiting membrane was presumably due to metabolic exchange with the vitreous cavity (Tascopoulos et al., 1976); this survival of some axons within small infarcts influences the effect of focal retinal ischaemia on visual function (McLeod, 1976).

NATURE OF RETINAL COTTON-WOOL SPOTS Cotton-wool spots have been recognised as distinct ophthalmoscopic entities for over a century, yet the pathogenesis of these lesions has not been fully appreciated until now. Our studies indicate that cotton-wool spots should be regarded as localised accumulations of axoplasmic debris in the retinal nerve-fibre layer which result from interruption of organelle transport in ganglion-cell axons. Any factor responsible for focal interruption of axonal flow in the retinal nerve-fibre layer will give rise to similar accumulations, though clinically the cause is usually ischaemia (Fig. 15).

Dollery et al. (1966) had regarded the whole of ischaemic areas produced by microembolisation in
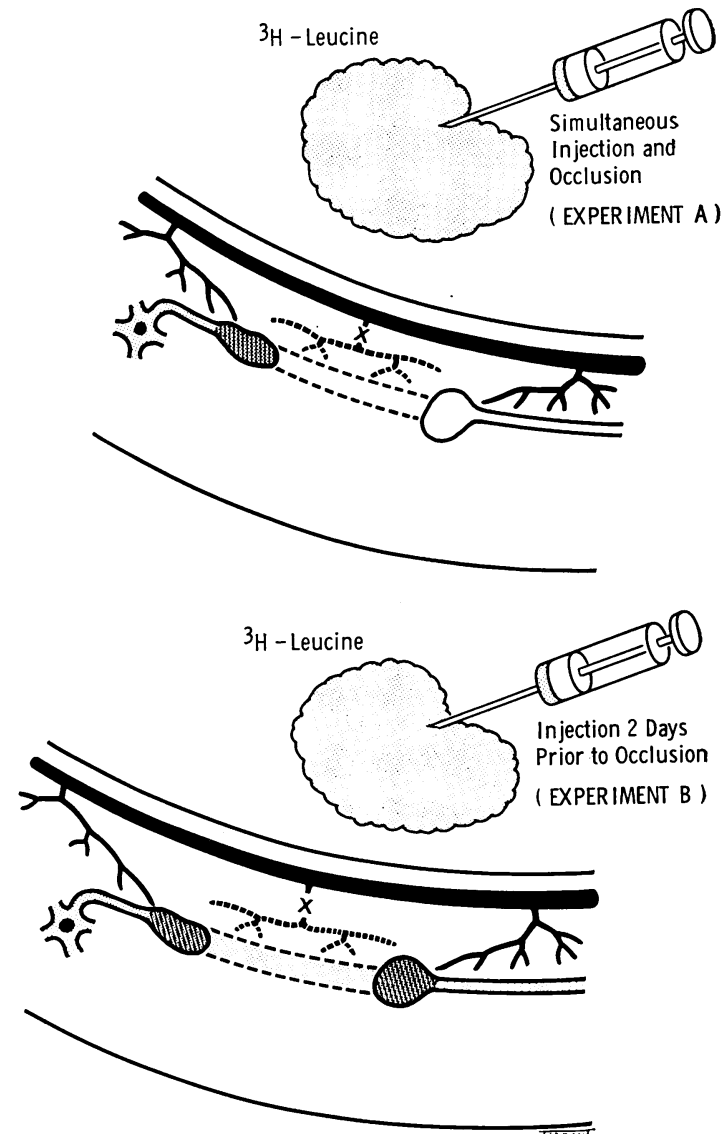

Fig. 14 Summary diagram of autoradiographic findings

pigs as 'cotton-wool spots'. However, our clinical and experimental observations demonstrate that no simple relationship exists between the size of the territory of an occluded vessel and the development of white (as opposed to grey) retinal swelling. The length of a cotton-wool spot (that is, the dimension at right-angles to the axis of ganglion-cell axons) reflects only the extent of that boundary of an ischaemic area which is crossed by retinal nerve fibres. The width of a cotton-wool spot (that is, the dimension along the axis of axons) depends on the distance that different axons penetrate an ischaemic area before axoplasmic transport is interrupted. The threshold of individual nerve fibres to anoxic damage is probably variable, and the local vitreal oxygen tension and capillary collateral blood flow may also be important in determining this dimension of the border zone. The degree of swelling and opacification of a cotton-wool spot reflects the amount of axoplasmic debris which accumulates; this is determined by the volume flow of axoplasm 
and so depends mainly on the thickness of the nerve-fibre layer at the boundary between viable and ischaemic retina.

In conclusion, therefore, cotton-wool spots are not 'microinfarcts' of the inner retina, as defined hitherto. The intra-axonal aggregation of organelles which we observed 2 days after retinal arteriolar occlusion was not itself a manifestation of neuronal hypoxia, but was merely a sequel to anoxic disruption of normal physiological processes in the contiguous segments of the axons. The accumulation of cytoplasmic debris (and development of opaque retinal swelling) was thus as much a reflection of continuing axoplasmic transport in unaffected parts of axons as of ischaemic necrosis of axon segments within the retinal infarct.

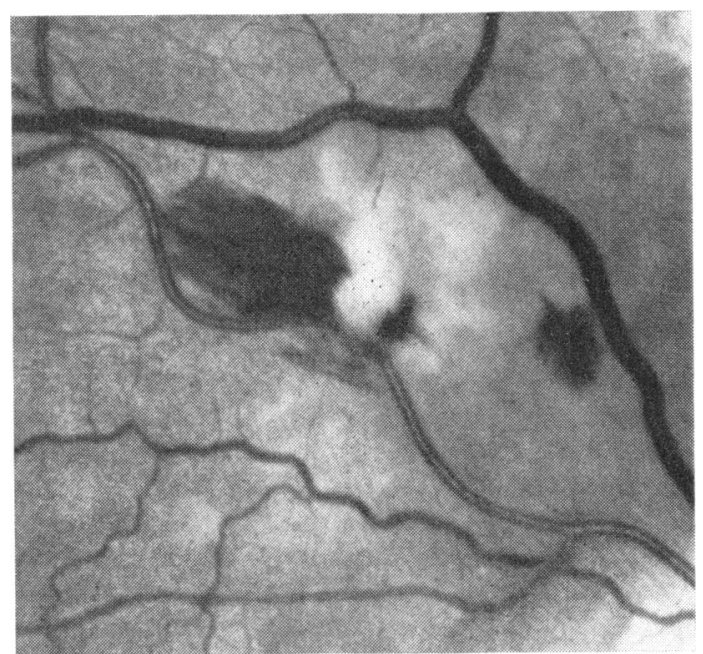

Fig. 15 Ischaemic lesion in a hypertensive patient: accumulations of white axoplasmic material on each side of a small retinal infarct; part of the zone $P Z$ is outlined by haemorrhage (Courtesy of Mr L. G. Fison)

We thank Miss E. Clarke and Mr P. L. Ansell for their help in electron microscopy and autoradiography, and Dr C. M. Kemp for both adapting his microspectrophotometer and patiently scanning our samples. Messrs R. Humphrey, K. Sehmi, and T. Tarrant assisted in the production of the illustrations. We are indebted to Miss I. F. Miller for her assistance in the preparation of the manuscript.

\section{References}

Anderson, D. R., and Hendrickson, A. (1974). Investigative Ophthalmology, 13, 771.

Ashton, N. (1970). British Medical Bulletin, 26, 143.

Ashton, N., and Harry, J. (1963). Transactions of the Ophthalmological Societies of the United Kingdom, 83, 91.

Ashton, N., et al. (1966). British Journal of Ophthalmology, 50, 283.

Banks, P., Mangnall, D., and Mayor, D. (1969). Journal of Physiology, 200, 745.

Bok, D., and Young, R. W. (1972). Vision Research, 12, 161.

Chou, S. M. (1970). Neurology (Minneapolis), 20, 601.

Dollery, C. T., et al. (1966). British Journal of Ophthalmology, $50,285$.

Goldberg, S., and Galin, M. A. (1973). Investigative Ophthalmology, 12, 382.

Gupta, B. L., Morton, R. B., and Cooper, N. C. (1973). Journal of Microscopy, 99, 1.

Hendrickson, A. (1972). Journal of Comparative Neurology, 144, 381.

Jeffrey, P. L., and Austin, L. (1973). Progress in Neurobiology, 2, 207.

Kohner, E. M., et al. (1970). American Journal of Ophthalmology, 69, 778.

Lasek, R. J. (1967). Nature, 216, 1212.

Lubinska, L. (1964). Progress in Brain Research, 13, 1.

McEwen, B. S., and Grafstein, B. (1968). Journal of Cellular Biology, 38, 494.

McLeod, D. (1975). Lancet, 2, 954.

McLeod, D. (1976). Transactions of the Ophthalmological Societies of the United Kingdom, 96, 313.

Marshall, J. (1970). Investigative Ophthalmology, 9, 97.

Marshall, J., and Faulkner, D. (1977). Journal of Microscopy, in press.

Marshall, J., and Voaden, M. J. (1974). Investigative Ophthalmology, 13, 602.

Ochs, S. (1975). Journal of Physiology, 253, 459.

Okun, E., and Collins, E. M. (1962). American Journal of Ophthalmology, 54, 786.

Perroncito, A. (1907). Beiträge zur pathologischen Anatomie und zur allgemeinen Pathologie, 42, 354.

Ramon Y Cajal, S. (1928). Degeneration and Regeneration of the Nervous System, p. 119. Translated by R. M. May. London, Oxford University Press.

Salpeter, M. M., Bachmann, L., and Salpeter, E. E. (1969). Journal of Cellular Biology, 41, 1.

Shakib, M., and Ashton, N. (1966). British Journal of Ophthalmology, 50, 325.

Tascopoulos, M., et al. (1976). In Vision and Circulation: Proceedings of the 3rd William Mackenzie Memorial Symposium, p. 93 . Edited by J. S. Cant. London, Kimpton.

Tso, M. (1976). Transactions of the Ophthalmological Societies of the United Kingdom, in press.

Wolter, J. R. (1959). American Journal of Ophthalmology, 48, 473.

Wolter, J. R., and Moorman, L. T. (1966). Archives of Ophthalmology, 76, 385.

Zelena, J. (1968). Zeitschrift für Zellforschung und mikroskopische Anatomie, 92, 186. 